\title{
PI3K inhibitor LY294002, as opposed to wortmannin, enhances AKT phosphorylation in gemcitabine-resistant pancreatic cancer cells
}

\author{
YUFENG WANG $^{1}$, YASUHIRO KURAMITSU ${ }^{1}$, BYRON BARON ${ }^{1,2}$, TAKAO KITAGAWA ${ }^{1}$, KAZUHIRO TOKUDA ${ }^{1}$ \\ JUNKO AKADA $^{1}$, SHIN-ICHIRO MAEHARA ${ }^{3}$, YOSHIHIKO MAEHARA ${ }^{2}$ and KAZUYUKI NAKAMURA ${ }^{1,4}$ \\ ${ }^{1}$ Department of Biochemistry and Functional Proteomics, Yamaguchi University Graduate School of Medicine, Ube, \\ Yamaguchi, Japan; ${ }^{2}$ Centre for Molecular Medicine and Biobanking, University of Malta, Msida, Republic of Malta; \\ ${ }^{3}$ Department of Surgery and Science, Graduate School of Medical Science, Kyusyu University, Fukuoka; \\ ${ }^{4}$ Centre of Clinical Laboratories in Tokuyama Medical Association Hospital, Shunan, Yamaguchi, Japan
}

Received September 13, 2016; Accepted November 22, 2016

DOI: 10.3892/ijo.2016.3804

\begin{abstract}
LY294002 and wortmannin are chemical compounds that act as potent inhibitors of phosphoinositide 3-kinases (PI3Ks). Both of them are generally used to inhibit cell proliferation as cancer treatment by inhibiting the PI3K/ protein kinase B (AKT) signaling pathway. In this study, LY294002 (but not wortmannin) showed an abnormal ability to enhance AKT phosphorylation (at Ser472) specifically in gemcitabine (GEM)-resistant pancreatic cancer (PC) cell lines PK59 and KLM1-R. LY294002 was shown to activate AKT and accumulate phospho-AKT at the intracellular membrane in PK59, which was abolished by treatment with AKTi-1/2 or wortmannin. Inhibiting AKT phosphorylation by treatment with AKTi-1/2 or wortmannin further enhanced LY294002-induced cell death in PK59 and KLM1-R cells. In addition, treatment with wortmannin alone failed to inhibit cell proliferation in both PK59 and KLM1-R cells. Thus, our results reveal that LY294002 displays the opposite effect on PI3K-dependent AKT phosphorylation, which maintains cell survival from the cytotoxicity introduced by LY294002 itself in GEM-resistant pancreatic cancer cells. We suggest that targeting the PI3K/AKT signaling pathway with inhibitors may be counterproductive for patients with PC who have acquired GEM-resistance.
\end{abstract}

Correspondence to: Dr Yasuhiro Kuramitsu, Department of Biochemistry and Functional Proteomics, Yamaguchi University Graduate School of Medicine, 1-1-1 Minami-Kogushi, Ube, Yamaguchi 755-8505, Japan

E-mail: climates@yamaguchi-u.ac.jp

Abbreviations: PC, pancreatic cancer; PI3K, phosphoinositide 3-kinase; AKT, protein kinase B; GEM, gemcitabine

Key words: LY294002, wortmannin, gemcitabine, pancreatic cancer, AKT phosphorylation

\section{Introduction}

Phosphoinositide 3-kinases (PI3Ks) are a family of enzymes which are involved in cellular functions, such as cell growth, proliferation, differentiation and intracellular trafficking, which in turn contribute to cancer (1). Class $\mathrm{I}_{\mathrm{A}}$ PI3Ks, which consist of a regulatory subunit (p85) and a catalytic subunit (p110), are frequently mutated in human cancers and many of these mutations cause the kinases to become more active (2-5).

PI3Ks can be activated by growth factor stimulation, which results in the phosphorylation of phosphatidylinositol 4,5-bisphosphate $\left(\mathrm{PIP}_{2}\right)$ to produce phosphatidylinositol 3,4,5-bisphosphate $\left(\mathrm{PIP}_{3}\right)(6) . \mathrm{PIP}_{3}$ directly binds phosphoinositide-dependent kinase 1 (PDK1) and protein kinase $\mathrm{B}$ (AKT), causing the colocalization of activated PDK1 with AKT, which allows AKT phosphorylation on threonine 308 (T308) by PDK1 $(7,8)$. Complete activation of AKT occurs by phosphorylation on serine 473 (S473) by mammalian target of rapamycin (mTOR)containing protein complex 2 (mTORC2) (9). PI3K/AKT signaling is closely associated to cellular proliferation and survival through several mechanisms, such as inhibition of pro-apoptotic B-cell lymphoma 2 (Bcl-2) family members $\mathrm{BAD}$ and $\mathrm{BAX}$, activation of transcription factor $\mathrm{NF}-\kappa \mathrm{B}$, suppression of p53 by phosphorylating E3 ubiquitin-protein ligase $(\mathrm{Mdm} 2)$ and promotion of protein synthesis by stimulating mTORC1 $(6,10,11)$.

Because inhibition of PI3K signaling can diminish cell growth and promote cell death, targeting the PI3K signaling pathway by inhibitors is being evaluated in clinical trials for cancer therapeutics. Preclinical studies have shown that PI3K pathway inhibitors have remarkable curative effects in several types of cancer, such as human epidermal growth factor receptor 2 (HER2)-amplified breast cancers, cancers with PIK3CA mutations and phosphatase and tensin homolog (PTEN)-deficient cancers (12-14).

Several reports have shown that PI3K inhibitors could be used as adjuvant therapy for pancreatic cancer, as it improved the anticancer drug efficacy by inhibiting the PI3K pathway and extended the overall survival in mouse models (15-18). In 
this study, however, the PI3K inhibitor LY294002 has been shown to enhance PI3K-dependent AKT phosphorylation in pancreatic cancer cells. Interestingly, this phosphorylation induced by LY294002 only occurs once the cells have gained GEM-resistance. Moreover, inhibition of PI3K by treatment with wortmannin did not induce any apparent cytotoxicity in GEM-resistant cells. Our data indicate that the uncertainty and risk is still high for treating PC by using PI3K inhibitors.

\section{Materials and methods}

Cell lines. All cell lines were obtained from Cell Resource Center for Biomedical Research Institute of Development, Aging and Cancer, Tohoku University. Cells were cultured in Roswell Park Memorial Institute-1640 (RPMI-1640; Gibco, 05918, Gaithersburg, MD, USA) medium supplemented with $10 \%$ heat-inactivated fetal bovine serum (FBS; Gibco, 26140-079) and $21 \mathrm{mM}$ of L-glutamine, at $37^{\circ} \mathrm{C}$, in a humidified 5\% $\mathrm{CO}_{2}-95 \%$ air mixture. GEM-resistant cells derived from KLM1 (KLM1-R) was established as previous descriptions $(19,20)$. KLM1 cells were tretaed with $10 \mu \mathrm{g} / \mathrm{ml}$ of GEM for 2 weeks, after which, cells were washed and resuspended in fresh medium. This was followed by a 2 -week culture period which served as a recovery procedure. This procedure was repeated for another 3 cycles.

Materials. LY294002 (9901) and wortmannin (9951S) were purchased from Cell Signaling Technology (Boston, MA, USA). AKTi-1/2 (ab142088) was purchased from Abcam Biochemicals (Cambridge, MA, USA). Epithelial growth factor (E9644) was purchased from Sigma (St. Louis, MO, USA). The antibodies specific for p-ERK ${ }^{\mathrm{T} 204 / 202}$ (sc-7383), ERK (sc-94200), Hsp27 (sc-13132) and actin (sc-1616) were purchased from Santa Cruz Biotechnology (Santa Cruz, CA, USA). The antibodies specific for Src (Src Antibody Sampler kit, 9935), p-Hsp27 $7^{\mathrm{S} 78}$ (2405), p-Hsp27 ${ }^{\mathrm{S} 82}$ (2401), PTEN (9552S), AKT (9272) and p-AKT ${ }^{\mathrm{S} 473}$ (4058) were purchased from Cell Signaling Technology.

Western blotting. Total protein was extracted from the cells using lysis buffer (1\% NP-40, $1 \mathrm{mM}$ sodium vanadate, $11 \mathrm{mM}$ PMSF, $501 \mathrm{mM}$ Tris, $101 \mathrm{mM}$ NaF, $101 \mathrm{mM}$ EDTA, $1651 \mathrm{mM}$ $\mathrm{NaCl}, 10 \mu \mathrm{g} / \mathrm{ml}$ leupeptin, and $10 \mu \mathrm{g} / \mathrm{ml}$ aprotinin) (21). Equal amounts of protein $(20 \mu \mathrm{g})$ were resolved by $5-20 \%$ SDS-polyacrylamide gel and then transferred onto PVDF membrane (Immobilon-P; Millipore, Bedford, MA, USA). The membrane was incubated with a primary antibody at $4^{\circ} \mathrm{C}$ overnight and a horseradish peroxidase (HRP)-conjugated secondary antibody for $1 \mathrm{~h}$ at room temperature. The immunoblots were visualized with a chemiluminescent reagent (Immunostar, Wako, Osaka, Japan) and detected by using an Image Reader LAS-1000 Pro (Fujifilm Corp., Tokyo, Japan).

Immunofluorescence. Cells were cultured on coverslips in 12 -well plates at a density of $1 \times 10^{5}$ cells per well. Cells were fixed using fresh $3.7 \%$ paraformaldehyde in phosphate-buffered saline (PBS) and permeabilized with $0.1 \%$ Triton X-100. After washing with PBS they were incubated in blocking solution (1\% goat serum or $1 \%$ donkey serum in PBS with $0.1 \%$ Tween-20) for $1 \mathrm{~h}$ at room temperature (22). Cells were treated with a primary antibody in blocking solution overnight at $4^{\circ} \mathrm{C}$ and a secondary antibody for $1 \mathrm{~h}$ at room temperature. Cell nuclei were counter-stained with $1.43 \mu \mathrm{M}$ DAPI (4,6'-diamidino-2-phenylindole). Confocal images were obtained by using Laser Scan Confocal Microscope (LSM 510 META; Carl Zeiss, Mobicity, Australia).

Cell proliferation assay. Cells were cultured in 96-well plates. After treatment, $20 \mu \mathrm{l}$ of the 3-(4,5-dimethylthiazol-2-yl)5(3-carboxymethonyphenol)-2-(4-sulfophenyl)-2H-tetrazolium (MTS) dye (Promega, Madison, WI, USA) was added to each well of the plate and incubated for $2 \mathrm{~h}$ at $37^{\circ} \mathrm{C}$, in a humidified $5 \% \mathrm{CO}_{2}-95 \%$ air mixture. Optical density (OD) was read directly at $492 \mathrm{~nm}$ using the iMark $^{\mathrm{TM}}$ microplate absorbance reader (Bio-Rad, Hercules, CA, USA). Each experiment was repeated three times.

\section{Results}

The PI3K inhibitor LY294002 (but not wortmannin) enhances AKT phosphorylation in PK59 cells. The effect of the PI3K inhibitor, LY294002, on AKT phosphorylation at serine 473 in PC PK59 cells was detected by western blot analysis. Unexpectedly, p-AKT was significantly increased rather than decreased by treatment with LY294002 for $24 \mathrm{~h}$ in a dosedependent manner and over a time course (Fig. 1A and C). LY294002 was also shown to enhance epithelial growth factor (EGF)-triggered AKT phosphorylation (Fig. 1B). However, the other PI3K inhibitor, wortmannin, showed the expected performance in inhibiting the PI3K/AKT pathway (Fig. 1B and $\mathrm{C}$ ). Interestingly, the effect of wortmannin on inhibiting AKT phosphorylation was weakened after $6 \mathrm{~h}$ of treatment and completely disappeared after $24 \mathrm{~h}$ (Fig. 1C). In addition, the phosphorylation of tyrosine-protein kinase CSK ( $\mathrm{Src}$ ), extracellular regulated protein kinases (ERK) and heat shock protein 27 (Hsp27), which have been shown to be involved in AKT activation (23-26), were not altered by treatment with LY294002 (Fig. 1D). These results indicate that LY294002, but not wortmannin, displays the opposite function to that expected in regulating the PI3K/AKT signaling pathway in PK59 cells.

LY294002-induced AKT phosphorylation specifically occurs in GEM-resistant PC cells. LY294002, as well as wortmannin, have shown their ability to inhibit PI3K/AKT activity in HeLa and HEK293 cells (Fig. 2A and B). LY294002 could also inhibit AKT phosphorylation in various types of PC cancer cell lines, such as in Panc-1, MIA-PaCa-2, AsPC-1 and BxPC-3 cells (27-29). We previously reported that PK59 is much less sensitive to GEM ( $\left.\mathrm{IC}_{50}, 294.72 \mu \mathrm{g} / \mathrm{ml}\right)$ than Panc-1 $\left(\mathrm{IC}_{50}, 8.07 \mu \mathrm{g} / \mathrm{ml}\right), \mathrm{MIA}-\mathrm{PaCa}-2$ ( $\left.\mathrm{IC}_{50}, 6.81 \mu \mathrm{g} / \mathrm{ml}\right)$, AsPC-1 $\left(\mathrm{IC}_{50}, 1.05 \mu \mathrm{g} / \mathrm{ml}\right)$ or BxPC-3 $\left(\mathrm{IC}_{50}, 6.67 \mu \mathrm{g} / \mathrm{ml}\right)$ cells (30). We thus tested whether LY294002-induced AKT phosphorylation specifically occurs in GEM-resistant PC cells. A GEM-resistant PC cell line KLM1-R has been established by culturing the gemcitabine-sensitive KLM1 cells with $10 \mu \mathrm{g} / \mathrm{ml}$ of GEM $(19,20)$, as shown (Fig. 2C). As hypothesized, upregulation of p-AKT instead of downregulation was observed by treatment with LY294002 in GEM-resistant KLM1-R compared to KLM1 cells in a dose-dependent manner (Fig. 2D). These 
$\mathbf{A}$

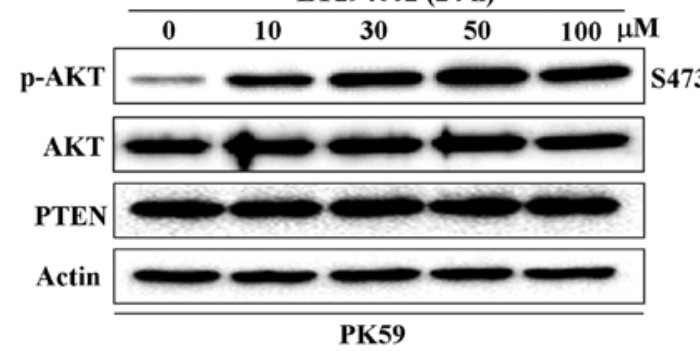

B

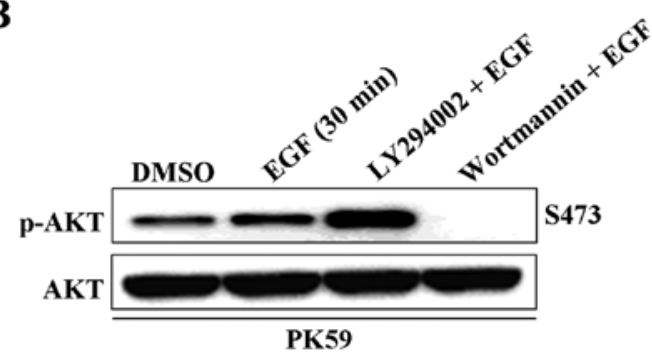

D

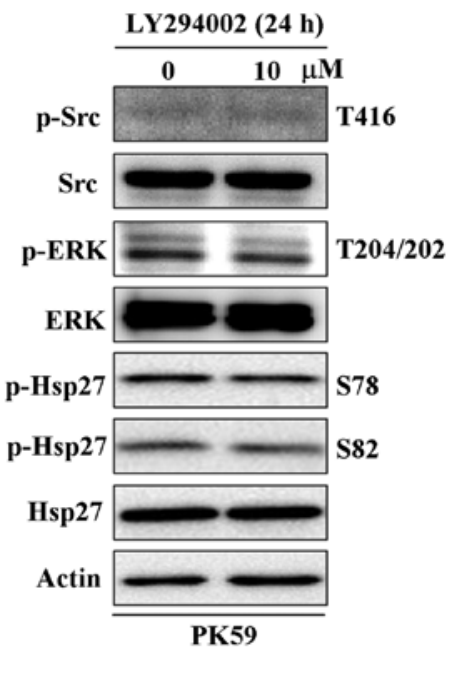

C

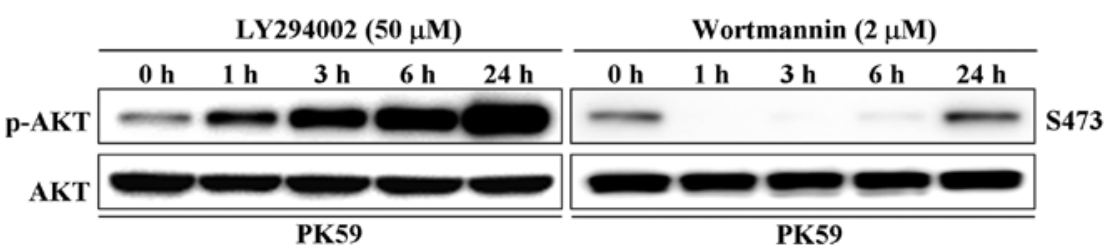

Figure 1. LY294002 induces upregulation of p-AKT in PC PK59 cells. (A) PK59 cells were treated with different dose of LY294002 for 24 h. (B) PK59 cells were treated with $1 \mu \mathrm{g} / \mathrm{ml}$ of EGF for $30 \mathrm{~min}$ in the presence of $50 \mu \mathrm{M}$ of LY294002 or $2 \mu \mathrm{M}$ of wortmannin. (C) PK59 cells were treated with LY294002 or wortmannin in a time course. (D) PK59 cells were treated with $10 \mu \mathrm{M}$ of LY294002 for $24 \mathrm{~h}$.
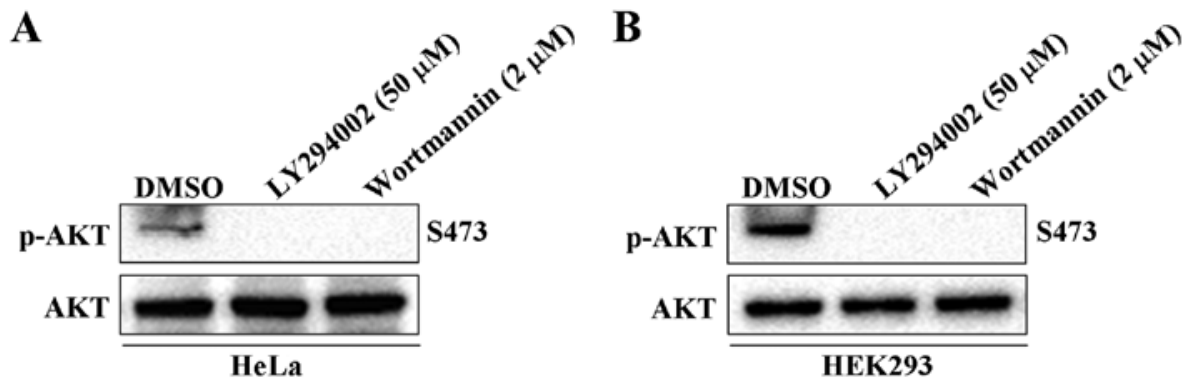

C

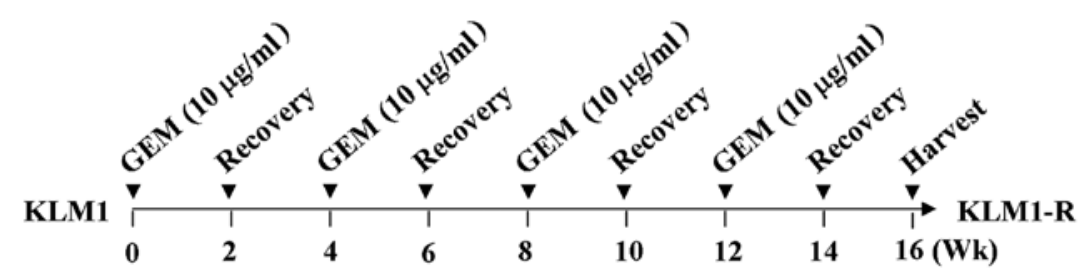

D

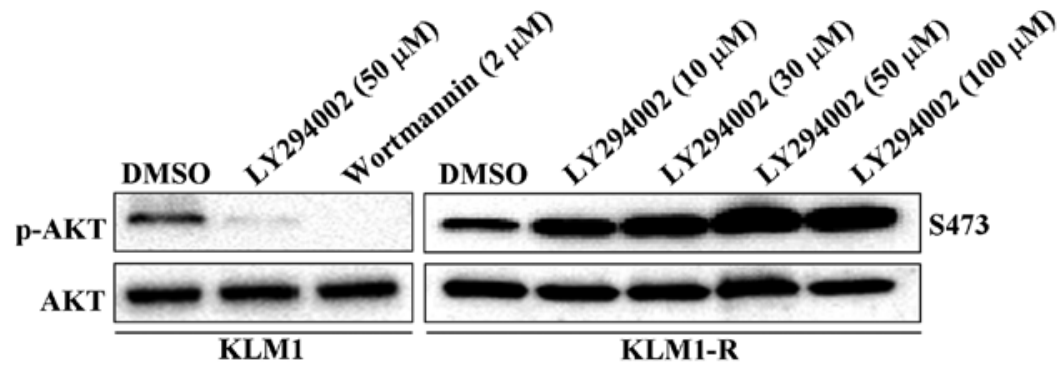

Figure 2. LY294002 induces AKT phosphorylation specifically in GEM-resistant PC cells. (A and B) HeLa and HEK293 cells were treated with $50 \mu \mathrm{M}$ of LY294002 or $2 \mu \mathrm{M}$ of wortmannin for $6 \mathrm{~h}$. (C) The scheme indicates a process of the acquirement of GEM-resistance for PC KLM1 cells. (D) KLM1 and KLM1-R cells were treated with LY294002 or wortmannin for $6 \mathrm{~h}$. 


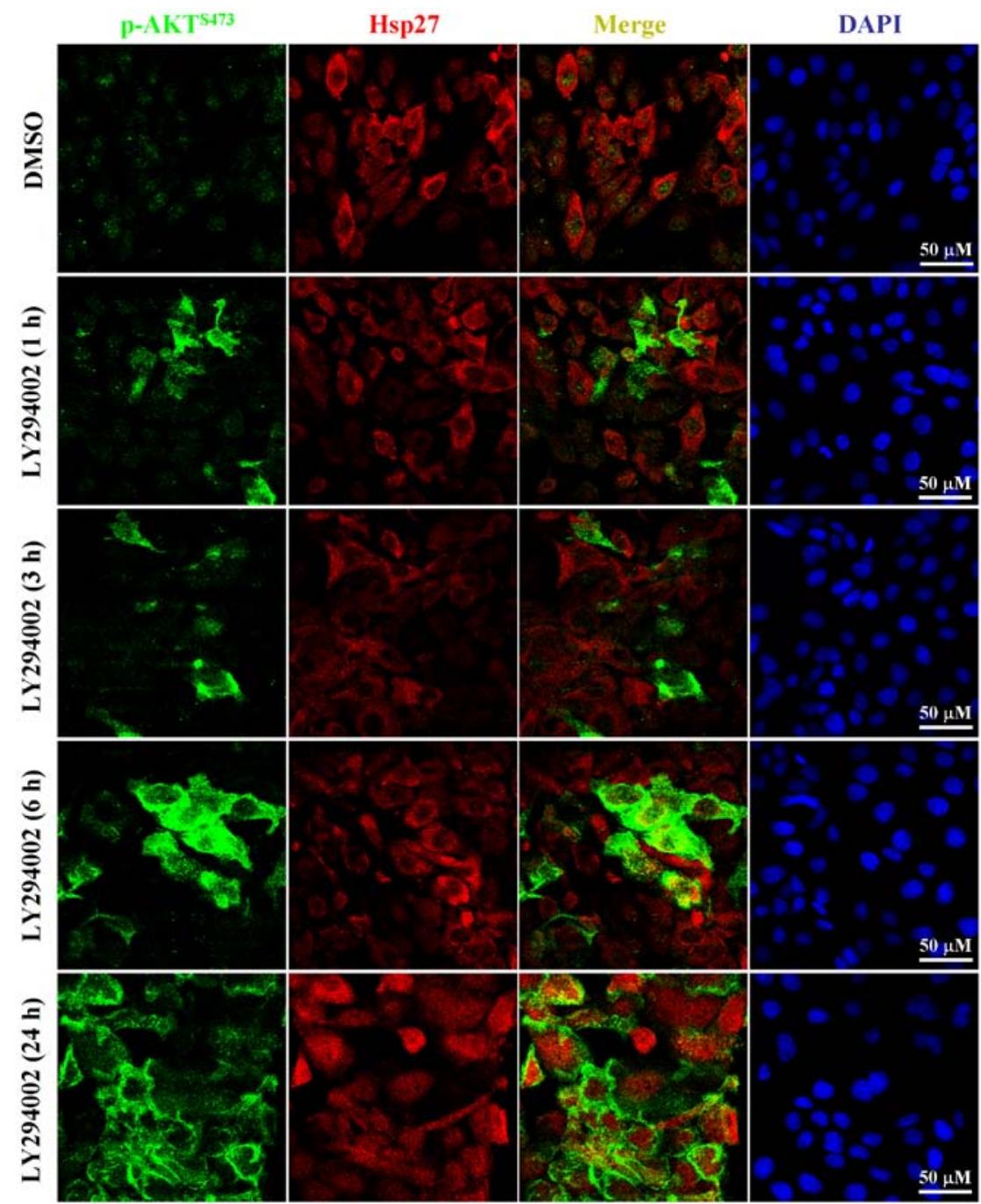

Figure 3. LY294002 induces the membrane localization of p-AKT. Immunofluorescent analysis was performed with anti-p-AKT and Hsp27 antibody by confocal microscope after cells were treated with $50 \mu \mathrm{M}$ of LY294002 in a time course. Green, p-AKT; red, Hsp27; blue, DAPI.
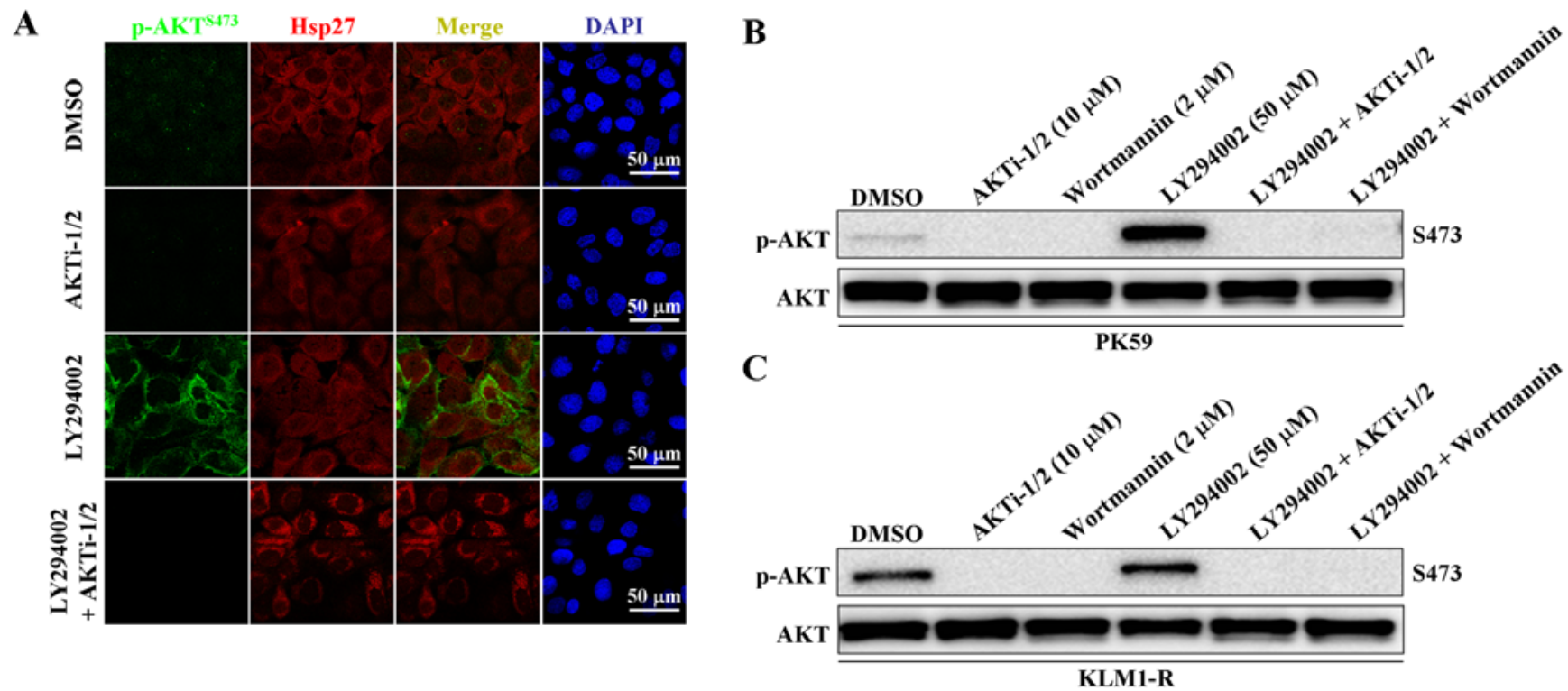

Figure 4. LY294002-induced AKT phosphorylation depends on PI3K. (A) Immunofluorescent analysis was performed with anti-p-AKT and Hsp27 antibody by confocal microscope after cells were treated with either $50 \mu \mathrm{M}$ of LY294002 or $10 \mu \mathrm{M}$ AKTi-1/2, or both for $24 \mathrm{~h}$. (B and C) PK59 and KLM1-R cells were treated with LY294002 alone or combined with either wortmannin or AKTi-1/2 for $3 \mathrm{~h}$. 
$\mathbf{A}$

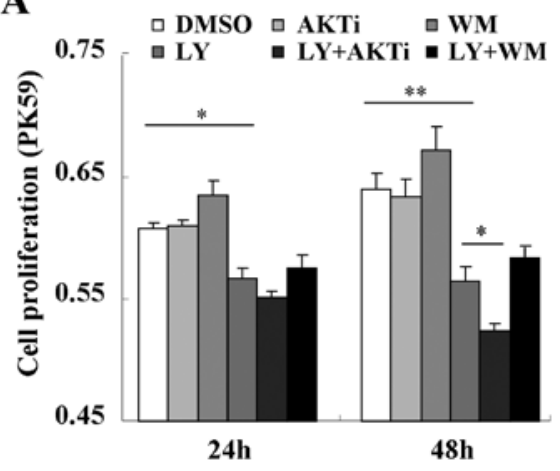

C

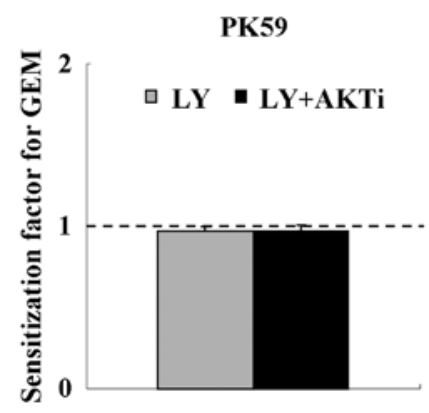

D
B
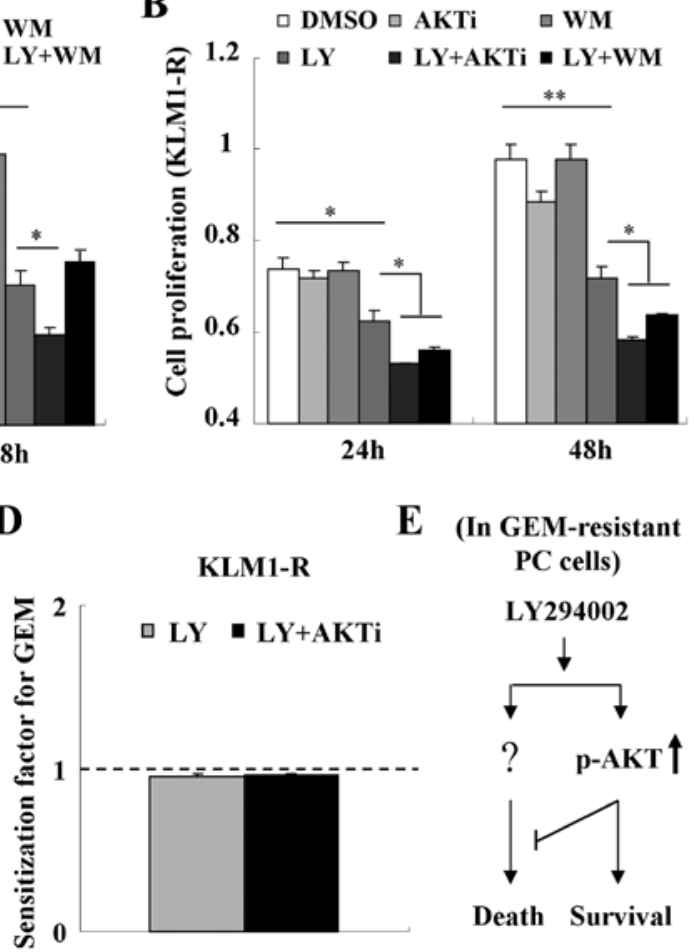

E (In GEM-resistant PC cells)

LY294002

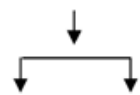

?

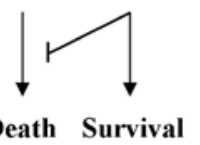

Figure 5. LY294002-induced AKT phosphorylation is associated with cell survival. (A and B) Proliferation assays were performed after PK59 and KLM1-R cells were treated with LY294002 alone or combined with either wortmannin or AKTi-1/2. ${ }^{* *} \mathrm{p}<0.01 ;{ }^{* * * *} \mathrm{p}<0.001$. (C and D) Proliferation assays were performed after PK59 and KLM1-R cells were treated with LY294002 alone or combined with AKTi-1/2 in the presence or absence of $10 \mu \mathrm{g} / \mathrm{ml}$ of GEM. Sensitization factor indicates the ratio of cell viability (GEM/GEM + LY) or (GEM/GEM + LY + AKTi). (E) The scheme indicates the pathway of LY294002 on p-AKT in GEM-resistant PC cells. WM, wortmannin; LY, LY294002; AKTi, AKTi-1/2.

results suggest that the inhibiting ability of LY294002 on PI3K could be altered in PC, once cells acquire GEM-resistance. PI3K activity is required for the LY294002-induced AKT phosphorylation and associated intracellular membrane translocation.

Using immunofluorescent analysis, p-AKT could only be observed in the nuclei of untreated PK59 cells (Fig. 3). However, AKT phosphorylation was initiated in the cytoplasm of LY294002-treated cells and the p-AKT eventually translocated onto the intracellular membrane after treatment for $24 \mathrm{~h}$ (Fig. 3), indicating that the LY294002-induced p-AKT may have functions associated with this specific localization. This kind of phosphorylation and intracellular membrane translocation of AKT could be abolished by combined treatment with an AKT specific inhibitor, AKTi-1/2 (Fig. 4A). We next examined whether LY294002-induced AKT phosphorylation is mediated by PI3K. Following treatment with LY294002 alone, p-AKT was significantly upregulated, but following combined treatment with LY294002 and either AKTi-1/2 or wortmannin, p-AKT was completely inhibited in both PK59 and KLM1-R cells (Fig. 4B and C). These data reveal that LY294002-induced AKT phosphorylation and intracellular membrane translocation are still dependent on PI3K.

LY294002-induced AKT phosphorylation contributes to cell survival. We next assessed the role of LY294002-induced p-AKT in cell proliferation. Treatment with wortmannin was shown to increase or have no effect on cell proliferation in PK59 and KLM1-R cells, respectively (Fig. 5A and B), indicating that
GEM-resistant PC cells may also be resistant to the inhibitor of PI3K. Treatment with LY294002 alone significantly inhibited cell proliferation in PK59 and KLM1-R cells and this inhibition could be further enhanced by combined treatment with either AKTi-1/2 or wortmannin (Fig. 5A and B). These results indicate that LY294002-induced p-AKT plays a negative role in LY294002-triggered cytotoxicity in GEM-resistant PC cells. In addition, LY294002-induced p-AKT did not contribute to reducing the sensitivity of PK59 or KLM1-R cells to GEM (Fig. 5C and D).

\section{Discussion}

LY294002 is a synthetic compound that was designed as a PI3K inhibitor based on the flavonoid quercetin (31). Like most other protein kinase inhibitors, the mode of action of LY294002 is through competition with ATP for binding the PI3K active site (32). However, while quercetin is a broad-spectrum protein kinase inhibitor, LY294002 acts as a specific inhibitor for PI3K, with no inhibitory effect on other protein kinases such as the AMP-dependent protein kinase and c-Src (at a concentration of $50 \mathrm{mM}$ ) (31). Apart from PI3K, LY294002 has been shown to inhibit several key signaling components, such as NF- $\mathrm{B}$ (33), heat shock proteins 27 (HSP27) and 72 (HSP72), AKT phosphorylation and survivin (34).

Interestingly, LY294002 binds PI3K in a different orientation to quercetin by a $180^{\circ}$ rotation. When binding PI3K, LY294002 only occupies part of the active site of the catalytic domain, filling the space occupied by the ribose of the ATP 
molecule, without extending into the phosphate binding region. In comparison, wortmannin almost completely fits the active site of the catalytic domain of PI3K, inducing a fairly large conformational rearrangement. Moreover, wortmannin forms a covalent complex, which irreversibly inhibits PI3K (35). The covalently-linked complex is the reason why in this study a decrease in wortmannin activity over time was observed, as the irriversibly bound complex was degraded and free PI3K was replenished.

LY294002 is a promising therapeutic compound because it showed growth inhibitory effects on various types of cancer cells through the induction of apoptosis and cell cycle arrest or autophagy $(36,37)$. Apoptotic cell death by LY294002 is mainly driven via activation of AMPK $\alpha 1$ and inactivation of AKT (38), but can also be via NF- $\kappa \mathrm{B}$ (33). However, it can also act by reducing transforming growth factor $\beta$ (TGF $\beta$ )mediated epithelial to mesenchymal transition (EMT) (39), inhibiting fatty acid synthase or suppress metastasis $(40,41)$.

The available literature for the combinatorial treatment of pancreatic cancer by LY294002 and gemcitabine is plentiful. In pancreatic cancer cells, partial reversal of the EMT was accompanied by inhibition of cell invasion and migration as well as increased chemosensitivity to GEM, and the process was mediated by the phosphatidylinositol 3-kinase (PTEN)/ Akt signaling pathway (42). However, no importance appears to have been previously given to the effect of GEM-resistance to such treatment. The same can be said for most other flavonoids tested. One exception has been the treatment of GEM-resistant cell lines with GEM and apigenin (an isoconformer of the isoflavonoid genistein), which showed additive inhibition of cell proliferation compared to the use of either agent alone, via increased cell cycle arrest (at both the $\mathrm{S}$ and G2/M phases) as well as early apoptosis (by downregulation of pAkt) (43).

In conclusion, this is the first report to show that treatment of the GEM-resistant pancreatic cancer cell line PK59 with LY294002 (but not wortmannin) enhanced AKT phosphorylation specifically via PI3K and resulted in an associated translocation to the cell membrane. The overall effect of this LY294002-induced AKT phosphorylation on PK59 cells was an increase in cell survival. This should be an eye-opener for future clinical trials where the GEM-sensitivity of the tumor is not known.

\section{Acknowledgements}

This study was supported in part by Grants-in-Aid from the Ministry of Education, Science, Sports, and Culture of Japan (no. 24501352 to Yasuhiro Kuramitsu). Immunoblot detection by LAS-1000 was done at the Gene Research Centre of Yamaguchi University.

\section{References}

1. Yuan TL and Cantley LC: PI3K pathway alterations in cancer: Variations on a theme. Oncogene 27: 5497-5510, 2008.

2. Ikenoue T, Kanai F, Hikiba Y, Obata T, Tanaka Y, Imamura J, Ohta M, Jazag A, Guleng B, Tateishi K, et al: Functional analysis of PIK3CA gene mutations in human colorectal cancer. Cancer Res 65: 4562-4567, 2005.

3. Mizoguchi M, Nutt CL, Mohapatra G and Louis DN: Genetic alterations of phosphoinositide 3-kinase subunit genes in human glioblastomas. Brain Pathol 14: 372-377, 2004.
4. Samuels Y and Velculescu VE: Oncogenic mutations of PIK3CA in human cancers. Cell Cycle 3: 1221-1224, 2004.

5. Philp AJ, Campbell IG, Leet C, Vincan E, Rockman SP, Whitehead RH, Thomas RJ and Phillips WA: The phosphatidylinositol 3'-kinase p85alpha gene is an oncogene in human ovarian and colon tumors. Cancer Res 61: 7426-7429, 2001.

6. Cantley LC: The phosphoinositide 3-kinase pathway. Science 296: 1655-1657, 2002.

7. Alessi DR, James SR, Downes CP, Holmes AB, Gaffney PR, Reese CB and Cohen P: Characterization of a 3-phosphoinositidedependent protein kinase which phosphorylates and activates protein kinase Balpha. Curr Biol 7: 261-269, 1997.

8. Currie RA, Walker KS, Gray A, Deak M, Casamayor A, Downes CP, Cohen P, Alessi DR and Lucocq J: Role of phosphatidylinositol 3,4,5-trisphosphate in regulating the activity and localization of 3-phosphoinositide-dependent protein kinase-1. Biochem J 337: 575-583, 1999.

9. Sarbassov DD, Guertin DA, Ali SM and Sabatini DM: Phosphorylation and regulation of Akt/PKB by the rictor-mTOR complex. Science 307: 1098-1101, 2005.

10. Engelman JA, Luo J and Cantley LC: The evolution of phosphatidylinositol 3-kinases as regulators of growth and metabolism. Nat Rev Genet 7: 606-619, 2006.

11. Duronio V: The life of a cell: Apoptosis regulation by the PI3K/ PKB pathway. Biochem J 415: 333-344, 2008.

12. Engelman JA, Chen L, Tan X, Crosby K, Guimaraes AR, Upadhyay R, Maira M, McNamara K, Perera SA, Song Y, et al: Effective use of PI3K and MEK inhibitors to treat mutant Kras G12D and PIK3CA H1047R murine lung cancers. Nat Med 14: 1351-1356, 2008.

13. Serra V, Markman B, Scaltriti M, Eichhorn PJ, Valero V, Guzman M, Botero ML, Llonch E, Atzori F, Di Cosimo S, et al: NVP-BEZ235, a dual PI3K/mTOR inhibitor, prevents PI3K signaling and inhibits the growth of cancer cells with activating PI3K mutations. Cancer Res 68: 8022-8030, 2008.

14. She QB, Chandarlapaty S, Ye Q, Lobo J, Haskell KM, Leander KR, DeFeo-Jones D, Huber HE and Rosen N: Breast tumor cells with PI3K mutation or HER2 amplification are selectively addicted to Akt signaling. PLoS One 3: e3065, 2008.

15. Junttila MR, Devasthali V, Cheng JH, Castillo J, Metcalfe C, Clermont AC, Otter DD, Chan E, Bou-Reslan H, Cao T, et al: Modeling targeted inhibition of MEK and PI3 kinase in human pancreatic cancer. Mol Cancer Ther 14: 40-47, 2015.

16. Duong HQ, Kim HJ, Kang HJ, Seong YS and Bae I: ZSTK474, a PI3K inhibitor, suppresses proliferation and sensitizes human pancreatic adenocarcinoma cells to gemcitabine. Oncol Rep 27: 182-188, 2012.

17. Jung KH, Yan HH, Fang Z, Son MK, Lee H, Hong $S$ and Hong SS: HS-104, a PI3K inhibitor, enhances the anticancer efficacy of gemcitabine in pancreatic cancer. Int J Oncol 45: 311-321, 2014.

18. Cruceru ML, Enciu AM, Popa AC, Albulescu R, Neagu M, Tanase CP and Constantinescu SN: Signal transduction molecule patterns indicating potential glioblastoma therapy approaches. Onco Targets Ther 6: 1737-1749, 2013.

19. Iwasaki I, Sugiyama H, Kanazawa S and Hemmi H: Establishment of cisplatin-resistant variants of human neuroblastoma cell lines, TGW and GOTO, and their drug cross-resistance profiles. Cancer Chemother Pharmacol 49: 438-444, 2002.

20. Maehara S, Tanaka S, Shimada M, Shirabe K, Saito Y, Takahashi K and Maehara Y: Selenoprotein P, as a predictor for evaluating gemcitabine resistance in human pancreatic cancer cells. Int J Cancer 112: 184-189, 2004.

21. Wang Y, Kuramitsu Y, Tokuda K, Okada F, Baron B, Akada J, Kitagawa $\mathrm{T}$ and Nakamura K: Proteomic analysis indicates that overexpression and nuclear translocation of lactoylglutathione lyase (GLO1) is associated with tumor progression in murine fibrosarcoma. Electrophoresis 35: 2195-2202, 2014.

22. Wang Y, Kuramitsu Y, Tokuda K, Baron B, Kitagawa T, Akada J, Maehara S, Maehara Y and Nakamura K: Gemcitabine induces poly (ADP-ribose) polymerase-1 (PARP-1) degradation through autophagy in pancreatic cancer. PLoS One 9: e109076, 2014.

23. Choudhury GG, Mahimainathan L, Das F, Venkatesan B and Ghosh-Choudhury N: c-Src couples PI 3 kinase/Akt and MAPK signaling to PDGF-induced DNA synthesis in mesangial cells. Cell Signal 18: 1854-1864, 2006.

24. Moelling K, Schad K, Bosse M, Zimmermann S and Schweneker M: Regulation of Raf-Akt cross-talk. J Biol Chem 277: 31099-31106, 2002. 
25. Qi S, Xin Y, Qi Z, Xu Y, Diao Y, Lan L, Luo L and Yin Z: HSP27 phosphorylation modulates TRAIL-induced activation of Src-Akt/ERK signaling through interaction with $\beta$-arrestin2. Cell Signal 26: 594-602, 2014.

26. Zheng C, Lin Z, Zhao ZJ, Yang Y, Niu H and Shen X: MAPKactivated protein kinase-2 (MK2)-mediated formation and phosphorylation-regulated dissociation of the signal complex consisting of p38, MK2, Akt, and Hsp27. J Biol Chem 281: 37215-37226, 2006

27. Singh S, Srivastava SK, Bhardwaj A, Owen LB and Singh AP: CXCL12-CXCR4 signalling axis confers gemcitabine resistance to pancreatic cancer cells: A novel target for therapy. Br J Cancer 103: 1671-1679, 2010

28. Li W, Ma J, Ma Q, Li B, Han L, Liu J, Xu Q, Duan W, Yu S Wang F, et al: Resveratrol inhibits the epithelial-mesenchymal transition of pancreatic cancer cells via suppression of the PI-3K/ Akt/NF- $\kappa B$ pathway. Curr Med Chem 20: 4185-4194, 2013.

29. Fujiwara M, Izuishi K, Sano T, Hossain MA, Kimura S, Masaki T and Suzuki Y: Modulating effect of the PI3-kinase inhibitor LY294002 on cisplatin in human pancreatic cancer cells. J Exp Clin Cancer Res 27: 76, 2008.

30. Mori-Iwamoto S, Kuramitsu Y, Ryozawa S, Taba K, Fujimoto M, Okita K, Nakamura K and Sakaida I: A proteomic profiling of gemcitabine resistance in pancreatic cancer cell lines. Mol Med Rep 1: 429-434, 2008.

31. Vlahos CJ, Matter WF, Hui KY and Brown RF: A specific inhibitor of phosphatidylinositol 3-kinase, 2-(4-morpholinyl)-8phenyl-4H-1-benzopyran-4-one (LY294002). J Biol Chem 269: 5241-5248, 1994

32. Toledo LM, Lydon NB and Elbaum D: The structure-based design of ATP-site directed protein kinase inhibitors. Curr Med Chem 6: 775-805, 1999.

33. Grandage VL, Gale RE, Linch DC and Khwaja A: PI3-kinase/ Akt is constitutively active in primary acute myeloid leukaemia cells and regulates survival and chemoresistance via NF-kappaB, Mapkinase and p53 pathways. Leukemia 19: 586-594, 2005.

34. Ohnishi K, Yasumoto J, Takahashi A and Ohnishi T: LY294002, an inhibitor of PI-3K, enhances heat sensitivity independently of p53 status in human lung cancer cells. Int J Oncol 29: 249-253, 2006.
35. Walker EH, Pacold ME, Perisic O, Stephens L, Hawkins PT, Wymann MP and Williams RL: Structural determinants of phosphoinositide 3-kinase inhibition by wortmannin, LY294002, quercetin, myricetin, and staurosporine. Mol Cell 6: 909-919, 2000.

36. Shtivelman E, Sussman J and Stokoe D: A role for PI 3-kinase and PKB activity in the $\mathrm{G} 2 / \mathrm{M}$ phase of the cell cycle. Curr Biol 12: 919-924, 2002.

37. Xing C, Zhu B, Liu H, Yao H and Zhang L: Class I phosphatidylinositol 3-kinase inhibitor LY294002 activates autophagy and induces apoptosis through 553 pathway in gastric cancer cell line SGC7901. Acta Biochim Biophys Sin (Shanghai) 40: 194-201, 2008.

38. Lee YK and Park OJ: Regulation of mutual inhibitory activities between AMPK and Akt with quercetin in MCF-7 breast cancer cells. Oncol Rep 24: 1493-1497, 2010.

39. Bakin AV, Tomlinson AK, Bhowmick NA, Moses HL and Arteaga CL: Phosphatidylinositol 3-kinase function is required for transforming growth factor beta-mediated epithelial to mesenchymal transition and cell migration. J Biol Chem 275: 36803-36810, 2000.

40. Van de Sande T, De Schrijver E, Heyns W, Verhoeven G and Swinnen JV: Role of the phosphatidylinositol 3'-kinase/PTEN/ Akt kinase pathway in the overexpression of fatty acid synthase in LNCaP prostate cancer cells. Cancer Res 62: 642-646, 2002.

41. Cole GW Jr, Alleva AM, Zuo JT, Sehgal SS, Yeow WS, Schrump DS and Nguyen DM: Suppression of pro-metastasis phenotypes expression in malignant pleural mesothelioma by the PI3K inhibitor LY294002 or the MEK inhibitor UO126. Anticancer Res 26A: 809-821, 2006.

42. Yi XP, Han T, Li YX, Long XY and Li WZ: Simultaneous silencing of XIAP and survivin causes partial mesenchymalepithelial transition of human pancreatic cancer cells via the PTEN/PI3K/Akt pathway. Mol Med Rep 12: 601-608, 2015.

43. Strouch MJ, Milam BM, Melstrom LG, McGill JJ, Salabat MR, Ujiki MB, Ding XZ and Bentrem DJ: The flavonoid apigenin potentiates the growth inhibitory effects of gemcitabine and abrogates gemcitabine resistance in human pancreatic cancer cells. Pancreas 38: 409-415, 2009. 